\title{
ПРОФЕССИОНАЛЬНОЕ БЛАГОПОЛУЧИЕ СПЕЦИАЛИСТОВ С РАЗНЫМ УРОВНЕМ ДОВЕРИЯ ТЕХНИКЕ
}

Акимова А.Ю. (Нижегородский государственный университет им. Н.И. Лобачевского, Нижний Новгород, Россия) anna_ak@rambler.ru

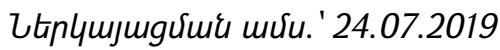

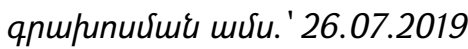

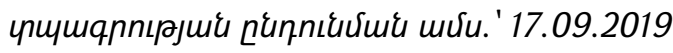

В статье представлены результаты исследования профессионального благополучия работников локомотивных бригад железнодорожного транспорта с разным уровнем доверия технике. Доверие технике рассматривается психологическим отношением специалиста к технике, возникающим и проявляющимся в результате взаимодействия с ней. Установлены нелинейные связи уровня доверия специалистов технике с показателями профессионального благополучия. При среднем и высоком уровне доверии технике удовлетворенность профессиональными достижениями, профессиональное самопринятие и общий показатель профессионального благополучия имеет более высокие значения, чем при низком уровне.

Ключевые слова: доверие спечиалиста технике, профессиональное благополучие, профрессиональное самопринятие, удовлетворенность профессиональными достижениями.

В работах, посвященных изучению доверия специалиста технике, приведены данные о его взаимосвязи с удовлетворенностью профессиональными достижениями и уверенностью специалиста в своем профессионализме, социально-психологическим климатом в коллективе, показателями субъективной оценки напряженности труда, т.е. с показателями, являющимися критериями профессионального благополучия специалиста $[1,6]$. Вместе с тем, некоторые авторы считают, что указанные критерии не в полной мере раскрывают структуру профессионального благополучия и недостаточно информативны с точки зрения его интегральной оценки [5]. Ими отмечается актуальность изучения всего многообразия факторов, оказывающих влияние на психологическое благополучие профессионала, что позволит приблизиться к единому пониманию данного концепта и его влиянию на все сфреры профессиональной деятельности [2].

Вообще, доверие специалиста технике и его значение в профессиональной деятельности, связанной с управлением сложными техническими объектами, является предметом изучения исследователей различных научных направлений. С

\footnotetext{
${ }^{4}$ Исследование выполнено при финансовой поддержке РФФИ (грант № 18-013-01021a).
} 
одной стороны, само социально-психологическое понятие доверия вызывает дискуссию ученых о его применимости к неодушевленным объектам. С другой, интерес вызывают функции и проявления феномена доверия технике в различных, в том числе сложных, условиях деятельности. В связи с этим, возникает вопрос о роли и значении доверия технике в системе функционирования специалиста в профессиональной сфере деятельности, в частности - о соотношении степени доверия технике и уровня профессионального благополучия.

В научных работах по проблеме доверия человека технике подчеркивается многомерность и сложность данного феномена, в связи с чем имеется множество подходов к его изучению [3, 7,8,9,10, и др.].

В данном исследовании мы придерживаемся понимания доверия технике как психологического отношения специалиста к технике, возникающего и проявляющего во взаимодействии с ней. Доверие технике как психологическое отношение включает когнитивный (представления о характеристиках техники, способствующих решению определенных, в частности, профессиональных, задач с ее помощью), эмоциональный (переживания по поводу взаимодействия с техникой) и поведенческий (особенности поведения при ее эксплуатации в различных условиях) компоненты. Такое понимание доверия технике было теоретически обосновано и эмпирически подтверждено в ранее проведенных исследованиях [1, 4, и др.].

Цель представленного исследования заключалась в изучении профессионального благополучия у специалистов с разным уровнем доверия эксплуатируемой ими технике.

Уровень доверия технике оценивался с использованием авторского опросника «Доверие специалиста технике», разработанного для оценки доверия технике специалистов, деятельность которых связана с взаимодействием со сложными техническими объектами. Стимульный материал опросника содержит 18 утверждений, оцениваемых испытуемыми по степени согласия с ними по 5-ти бальной шкале Лайкерта. Каждое утверждение направлено на определение выраженности компонентов доверия технике - когнитивного, эмоционального, поведенческого. Общее расчетное значение показателя доверия специалиста технике переводится в стандартизированную шкалу стенов.

Профессиональное благополучие определялось с использованием «Методики оценки профессионального благополучия» - симметричной модификации методики психологического благополучия К. Риффр в адаптации Л.В. Жуковской, Е.Г. Трошихиной применительно к профессиональной деятельности (Рут, Августова, 2017). Методика позволяет оценить общий показатель профессионального благополучия и частные показатели по четырем шкалам: «Профессиональный рост», «Позитивные отношения с коллегами», «Профессиональное самопринятие» (субшкалы «Удовлетворенность уровнем компетентности» и «Удовлетворенность профессиональными достижениями»), «Автономность в профессиональной деятельности». 
В исследовании приняли участие 100 работников локомотивных бригад железнодорожного транспорта (машинистов и помощников машинистов) со стажем работы в должности от 1 года до 32 лет. Их деятельность связана с управлением поездным составом, представляющим собой сложный технический объект, и осуществляется, преимущественно, в сложных и неопределенных условиях.

Анализ показателей профессионального благополучия специалистов с разным уровнем доверия технике проводился с использованием оценки попарных различий по группам по критерию $U$ Манна-Уитни. Для статистической обработки результатов применялся программный пакет IBM SPSS Statistics 22.0. По результатам исследования, работники локомотивных бригад были отнесены к трем группам, различающимся уровнем доверия технике. К первой группе были отнесены 41 чел., имеющих высокие значения доверия технике (8-10 стен), ко второй - 33 чел., имеющих средние по уровню значения доверия технике (4-7 стен), к третьей - 26 чел., имеющих низкие значения доверия (1-3 стен).

Согласно полученным данным, имела место нелинейная связь профессионального благополучия участников исследования с уровнем доверия технике. В группе с низкими значениями доверия технике наблюдалось наиболее низкое значение профессионального благополучия, в группе со средними значениями доверия технике - значительно более высокое (различия достоверны по критерию Манна Уитни, $U=489$ при уровне статистической значимости $p=0,048)$. Значения профрессионального благополучия в группах со средним и высоким доверием технике статистически значимо не различалось.

Аналогичные нелинейные связи были выявлены по шкале «Профессиональное самопринятие»: при низком уровне доверия технике значения по этой шкале были самыми низкими, при среднем и высоком доверии - значительно выше $(U=433$, $\mathrm{p}=0,006)$. Дополнительно отметим, что по субшкале «Удовлетворенность профрессиональными достижениями», входящей в шкалу «Профессиональное самопринятие», были зафиксированы низкие показатели при низком доверии технике и значительно более высокие - при высоком доверии технике. (различия статистически значимы, $U=370, p=0,032)$.

По остальным шкалам профессионального благополучия значимых различий выявлено не было. Результаты исследования свидетельствуют о положительной нелинейной связи профессионального благополучия с уровнем доверия технике. Опираясь на эти данные, можно полагать, что указанная взаимосвязь у участников исследования была в значительной степени обусловлена степенью их удовлетворенности профессиональными достижениями как компонента профессионального самопринятия в структуре профессионального благополучия.

Возможно, что одним из оснований принятия и осознания себя компетентным, достигающим успеха профессионалом в любых трудовых ситуациях, является соответствующее отношение к средствам труда, в частности - эксплуатируемой 
технике. Можно предположить, что доверие технике, уверенность в ее надежности, предсказуемости, безопасности даже в самых сложных условиях работы повышает уверенность специалиста в собственной способности управлять ситуацией, применять свои знания, умения и навыки, используя позитивный опыт деятельности по управлению техникой. В случае низкого доверия технике, отношение к ней как ненадежной, небезопасной и непредсказуемой в критических ситуациях, возникающее при этом напряжение и опасение за невыполнение работы по «вине» техники, могут способствовать формированию неудовлетворенности собой как профессионалом, беспокойством за свое профессиональное будущее, отсутствием чувства контроля над обстоятельствами данной сферы жизнедеятельности и, как следствие, низким уровнем профессионального самопринятия, что ведет к снижению профессионального благополучия в целом.

Подводя итоги исследования, можно заключить, что среднее и высокое доверие работников локомотивных бригад эксплуатируемой технике способствует высокой удовлетворенности профессиональными достижениями, профессиональному самопринятию и профессиональному благополучию в целом. Низкое доверие технике приводит к низкой удовлетворенности профессиональными достижениями, низкому принятию себя в профессиональной сфере и, соответственно, низкому профессиональному благополучию. Таким образом, доверие специалиста технике можно считать одним из факторов профессионального благополучия.

В связи с тем, что в исследовании принимали участие представители только одной профессиональной группы - работники локомотивных бригад железнодорожного транспорта - затруднительно ответить на вопрос о том, являются ли выявленные связи общими для всех специалистов, профессиональная деятельность которых связана с взаимодействием со сложной техникой, либо эти связи специфичны для исследуемой профессиональной группы.

Учитывая вышеизложенное, к перспективным направлениям дальнейших исследований можно отнести изучение взаимосвязей психологического благополучия с доверием технике в зависимости от принадлежности специалиста к определенной профессиональной категории, вида эксплуатируемой технике. Практический интерес вызывает изучение таких взаимосвязей у специалистов с разным стажем работы, у мужчин и женщин, у специалистов с разными индивидуально-психологическими характеристиками и др.

\section{Литература}

1. Акимова А. Ю., Обознов А. А. Регулирующая функция отношения доверия работника технике в профессиональной деятельности //Вестник Тверского государственного университета. Серия: Педагогика и психология 2017.№ 2. С. 32-42. 
2. Бессонова Ю. В., Обознов А. А., Петрович Д.Л. Психологическое благополучие профессионала в организациях повышенного риска // Труды Третьей Международной научно-практической конференции «Человеческий фрактор в сложных технических системах и средах» (Эрго-2018) (СанктПетербург. Россия. 4-7 июля 2018) /Под ред. А.Н. Анохина. А.А. Обознова. П. И. Падерно. С. Ф. Сергеева.- СПб.: СПбГЭТУ «ЛЭТИ». Межрегиональная эргономическая ассоциация. 2018. - С. 627-634.

3. Купрейченко А. Б. Доверие и недоверие технике и социотехническим системам: обоснование методического подхода // Актуальные проблемы психологии труда. инженерной психологии и эргономики. Выпуск 4/ Под ред. В.А. Бодрова. А.Л. Журавлева. - М.: Изд-во «Институт психологии РАН». 2012. С. 331-350.

4. Обознов А. А.. Акимова А. Ю. Концептуальные основания и методический подход к изучению доверия работников технике (на примере машинистов локомотивных бригад) //Методы психологического обеспечения профрессиональной деятельности и технологии развития ментальных ресурсов человека/под ред. Дикой Л.Г.. Журавлева А.Л.. Холодной М.А. М: ИП РАН. Серия: «Фундаментальная наука - практике». 2014 г. С.62-75.

5. Рут Е. И., Августова Л. И. Профессиональное благополучие сотрудников коммерческих организаций: критерии и методика оценки / Научные исследования выпускников фракультета психологии СПБГУ. СПб: Изд-во: “СанктПетербургский государственный университет». 2017. Т. 5. С. 72-78.

6. Шатунова Е. А. Доверие работников к технике как фактор их отношения к труду. Дисс. ... канд. психол. наук. Тверь. 2015. 241с.

7. Jian J. Y. Bisantz A. M.. Drury C. G. Foundations for an empirically determined scale of trust in automated systems. International Journal of Cognitive Ergonomics. 2000. V. 4(1). P. 53-71.

8. Lee J., See K. Trust in technology: Designing for appropriate reliance // Human Factors. V. 46 (1). 2004. P. 50-58.

9. Lewandowsky S., Mundy M., Tan G.P.A. The dynamics of trust: Comparing humans to automation // Journ. of Experimental Psychology: Applied. 2000. V. 6. P.104-123.

10. Parasuraman R., Sheridan T., Wickens C. A model for types and levels of human interaction with automation. IEEE Transactions on Systems. Man. and Cybernetics. Part A: Systems and Humans. 2000. V. 30(3). P.P. 286-297. 


\section{OCCUPATIONAL WELL-BEING OF SPECIALISTS WITH DIFFERENT LEVEL OF TRUST TO EQUIPMENT}

Akimova A.Yu. (Lobachevsky State University of Nizhni Novgorod,

Nizhni Novgorod, Russia)

The results of the study of the occupational well-being of employees of locomotive railway brigades with different levels of trust to equipment are presented. The trust to equipment is considered a psychological attitude of the specialists to the technique, which arises and manifests as a result of interaction with it. The non-linear relationships of the level of trust of specialists to the equipment with indicators of occupational wellbeing have been established. If the trust to equipment is of medium or high level, satisfaction with professional achievements, professional self-acceptance and the overall indicator of occupational well-being has higher values than at low levels.

Keywords: confidence of a specialist in technology, professional well-being, professional self-acceptance, satisfaction with professional achievements. 